\title{
Awareness on Consequences of Teenage Pregnancy among Adolescent at Ampipal VDC, Gorkha
}

\author{
Sushila Devi Bhandari ${ }^{1}$ \\ ${ }^{1}$ PhD Scholar | Mewar University, Gangrar, Chittogar, Rajsthan India \\ ya_su_sa@hotmail.com
}

\begin{abstract}
Background: Teenage pregnancy is significant medical and social problem in many parts of the world. Complication of the child birth and unsafe abortion are among the main causes of death for women under 20. Early teenage pregnancy can cause severe health problems for both the mother and child. Moreover, an early start to childbearing greatly reduces women's educational and employment opportunities and is associated with higher levels of fertility. The objective of the study was to assess awareness on consequences of teenage pregnancy among adolescent of Ampipal VDC. Methods: Cross sectional descriptive study was used as research design. Interview questionnaire tool was used as an instrument for data collection. Systematic analysis of 100 respondents of Ampipal VDC was done and chi square test and awareness regarding consequences of teenage pregnancy of study population was examined using the SPSS (16.0). Results: The study revealed that more than half $(74 \%)$ had adequate knowledge on consequences of teenage pregnancy to mother and baby with mean score 12.34. More than of respondents (86\%) had adequate knowledge on cause of teenage pregnancy with mean score 6.38. Conclusion: The study concluded that half of respondent (74\%) had adequate knowledge on consequences of teenage pregnancy. There was statistical significance between educational level and knowledge on consequences of adolescent pregnancy whereas there was no association between knowledge and other socio demographic variables (ethnicity, family structure and occupation).
\end{abstract}

\section{KEYWORDS}

Adolescent, Awareness, Teenage pregnancy, Consequences of teenage pregnancy

\section{INTRODUCTION}

Nepal is one of the countries of predominance of traditional societies, where marriage and childbearing for many women still occur at an earlier age than the legal age of marriage, especially among certain ethnic groups. The mean age of marriage was 16.8, 17.2 and 17.8 in the years 1971, 1981 and 1991 respectively. Teenage childbearing is lowest in the Hill (16 percent) and highest in the Terai (18 percent); however, teenage pregnancy in the Terai zone has declined markedly, from 26 percent in 2001. Not surprisingly, early childbearing is inversely related to educational level. For example, teenagers with no education are about four times more likely to have begun childbearing than those with SLC and higher education (32 percent and 8 percent, respectively). The percentage of teenagers who have begun childbearing is highest ( 22 percent) in the middle wealth quintile and lowest in the wealthiest households ( 7 percent). At the national level, the proportion of teenage pregnancies has declined by about 10 percent in the last five years (NDHS, 2011, p.83).

Early marriage and childbearing are known to be associated with a low level of women's autonomy after marriage and high level of health risks among women and their children. Reducing the proportions of women marrying and giving birth while still in their teens, therefore, is a priority concern for population policies and programmemed (Choe et al, 2004, p. 17-18).

Adolescent pregnancy brings lost potentials (UNFPA, 2007a). Furthermore, it may bring many negative health and social effects for both mother and child (UNFPA 2007a). It is suggested that when a girl aged 15-19 years becomes pregnant is twice and an adolescent under 15 is five times more likely of dying during pregnancy or childbirth compared to a woman who gets pregnant above 20 years. School dropout, premature infant deaths, unhealthy children and giving birth to many 
children in a shorter period of time can be seen. Evidence indicates that becoming a mother during teenage years may pose many health risks such as anemia1, tearing of the vagina, fistula, mental disorders, puerperal sepsis, unsafe abortions and complications, pregnancy induced hypertension and many more due to physiological and psychological immaturity (WHO, 2008a).

Very little studies have been conducted on regarding awareness. It is important to have awareness on consequences of teenage pregnancy among adolescent. So, this study aims to assess the awareness of the teenage mother's on consequences of teenage pregnancy and child bearing also aims to bring up the real health issues that are degrading the health of the teenage pregnant/mothers and along with the possible solutions to address these issues.

\section{METHODS}

Simple descriptive cross-sectional research design was used to assess the awareness on teenage pregnancy among adolescents. Study area was Ampipal V.D.C of Gorkha District. Study population was female teenage aged between the ages 15-19 years of Ampipal VDC, Gorkha.

Probability simple random sampling technique was used by generating random number. Verbal consent was taken from participants and written permission was given by VDC. Simple random sampling method conducted and adolescent of 15-19 age group interviewed. The validity of the instrument was maintained by thoroughly reviewing the related literature and seeking opinion of the subject experts whereas the reliability of the instrument was maintained by pre-testing the instrument on the similar setting of the study and modification of the questionnaire was made accordingly.

Participants were interviewed using questionnaire, and data was collected on sociodemographic, awareness on sign and symptom of pregnancy and awareness on consequences of adolescent pregnancy on mother and child.

After data collection, questionnaire was rechecked for accuracy and completeness. A master sheet was prepared to enter data. Data were tabulated as per number of responses in master sheet for each questionnaire and were arranged and entered in SPSS 16.0 version for further analysis. Descriptive statistics and inferential statistics (chi-sqaure-test) were used for the analysis of data after entering into master sheet.

\section{RESUTLS}

Table 1. Demographic data of all the respondents $(n=100)$

\begin{tabular}{|l|l|l|l|l|}
\hline S.N. & \multicolumn{2}{|c|}{ Variables } & Frequency & Percentage (\%) \\
\hline 1. & Age & 15 years & 11 & 11 \\
& & $16 y e a r s$ & 16 & 16 \\
& & 17 years & 23 & 23 \\
& & 18 years & 24 & 24 \\
\hline 2. & Ethnicity & 19 years & 26 & 26 \\
& & Bhramin & 28 & 28 \\
& & Chhetri & 34 & 34 \\
& & Newar & 30 & 30 \\
\hline 3. & Education level & Others & Can Read and Write Only & 8 \\
& & Primary(1-8 class) & 30 & 10 \\
& & Secondary(9-10 class) & 34 & 30 \\
& & Higher Secondary(+2 and above) & 26 & 34 \\
\hline
\end{tabular}




\begin{tabular}{|l|l|l|l|l|}
\hline 4. & Religion & Hindu & 95 & 95 \\
\cline { 3 - 5 } & & Christian & 5 & 5 \\
\hline 5. & Marital Status & Married & 20 & 20 \\
& & Unmarried & 80 & 80 \\
\hline 6. & Occupation & Agriculture & 10 & 10 \\
& & Service & 2 & 2 \\
& & student & 78 & 78 \\
& & Housewife & 6 & 6 \\
\hline 7. & Type of Family & Others & 4 & 4 \\
\hline & & Single & 38 & 38 \\
& & Joint & 54 & 54 \\
\hline
\end{tabular}

Field Survey, 2013

Table 1 illustrates that out of 100 female of 15-19 years of age respondents, the mean age was $17.38 \pm 1.73$ (mean \pm SD). Thirty four percent $(34 \%)$ respondents were Chhetri followed by Newar (30\%) and Bhramin (28\%). The majority of respondents (95\%) were Hindu whereas $5 \%$ followed the Christianity. All of the respondents were literate in which more than half had secondary education $(34 \%)$ and more than $50 \%$ were students $(78 \%)$. Most of the respondents $(50 \%)$ were from joint family.

\section{Source of information regarding teenage pregnancy}

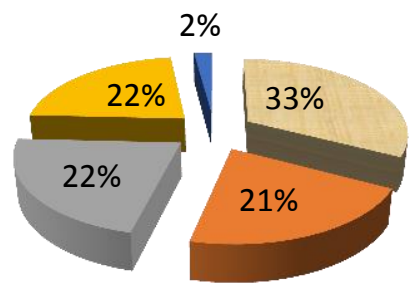

Television

Magazines/newspaper

Radio

Friends/Peers

- Other (books, school)

Figure 1 states the source of information regarding teenage pregnancy. It shows that most of the respondents (33\%) got information from television followed by Radio (22\%) friends/peers and magazine/ newspaper $(21 \%)$.

Table2. Respondent's knowledge regarding cause of teenage pregnancy $(\mathbf{n}=100)$

\begin{tabular}{|l|l|l|l|}
\hline S.N. & Causes of adolescent pregnancy & Frequency & $\begin{array}{l}\text { Percentage } \\
(\%)\end{array}$ \\
\hline 1. & Illiteracy & 92 & 92 \\
\hline 2. & Early age at marriage & 90 & 90 \\
\hline 3. & Lack of family support & 82 & 82 \\
\hline 4. & Poverty & 80 & 80 \\
\hline 5. & Low level of contraceptive use & 40 & 40 \\
\hline 6. & Exposure to violence & 46 & 46 \\
\hline 7. & Culture & 40 & 40 \\
\hline 8. & Having mother or sister who was adolescent mother & 44 & 44 \\
\hline
\end{tabular}




\begin{tabular}{|l|l|l|l|}
\hline 9. & Growing up in single parent & 34 & 34 \\
\hline
\end{tabular}

The above table reveals that majority (92\%) of respondent answered that illiteracy is a cause of teenage pregnancy. Minimum (34\%) of respondents responded that growing up in single parent also led to adolescent pregnancy. The total mean score regarding cause of adolescent pregnancy was 6.38 with standard deviation of 2.30 out of total score 9 which indicates that adolescent have adequate knowledge regarding cause of adolescent pregnancy.

Table 3: Respondent's knowledge regarding consequences of teenage pregnancy to mother $(\mathbf{n}=\mathbf{1 0 0})$

\begin{tabular}{|l|l|l|l|}
\hline S.N. & Consequences of teenage pregnancy to mother & Frequency & $\begin{array}{l}\text { Percentage } \\
(\%)\end{array}$ \\
\hline 1. & Maternal Death & 84 & 84 \\
\hline 2. & Abortion & 82 & 82 \\
\hline 3. & Obstructed Labour & 74 & 74 \\
\hline 4. & Operation (Caeserian Section) & 74 & 74 \\
\hline 5. & Anemia & 70 & 70 \\
\hline 6. & Episiotomy & 64 & 64 \\
\hline 7. & Pre-term Labour & 58 & 58 \\
\hline 8. & Instrument Delivery & 56 & 56 \\
\hline 9. & Pregnancy induced hypertension & 54 & 54 \\
\hline 10. & Eclampsia & 50 & 50 \\
\hline
\end{tabular}

Mean score \pm Standard deviation: $6.66 \pm 3.150$ Total score: 10

Field Survey, 2013

Table 3 illustrates that majority (84\%) of respondents knew that maternal death could occur as consequences of teenage pregnancy whereas just $50 \%$ of respondents answered that eclampsia is also one of the consequences of adolescent pregnancy. The total mean score regarding consequences of adolescent pregnancy to mother was 6.66 with standard deviation of 3.15 out of total score 10 which indicates that adolescent have adequate knowledge regarding consequences of adolescents pregnancy to mother.

Table 4. Respondent's knowledge regarding consequences of teenage pregnancy to baby $(\mathbf{n}=\mathbf{1 0 0})$

\begin{tabular}{|l|l|l|l|}
\hline S.N. & Consequences of teenage pregnancy to baby & Frequency & Percentage \\
\hline 1. & Neo-natal death & 86 & 86 \\
\hline 2. & Still Birth & 80 & 80 \\
\hline 3. & Low Birth Weight Baby & 76 & 76 \\
\hline 4. & Abnormal health condition & 76 & 76 \\
\hline 5. & Birth Asphyxia & 70 & 70 \\
\hline 6. & Low growth and development & 70 & 70 \\
\hline 7. & Pre-term Delivery & 66 & 66 \\
\hline 8. & CephaloPelvic Dispropotion & 44 & 44 \\
\hline
\end{tabular}

Mean score \pm Standard deviation: $5.68 \pm 2.53 \quad$ Total score: $8 \quad$ Field Survey, 2013

Table 4 illustrates that majority $(86 \%)$ of respondents knew that teenage pregnancy led to neonatal death. However, just $44 \%$ of respondents answered that cephalopelvic disproportion could occur as the consequences of adolescent pregnancy. The total mean score regarding consequences of adolescents pregnancy to baby was 5.68 with standard deviation of 2.53 out of total score 8 which 
indicates that the adolescents have adequate knowledge regarding the consequences of adolescent pregnancy to baby.

Table 5. Respondent's knowledge regarding preventive measure of teenage pregnancy $(n=100)$

Mean score \pm Standard deviation: $6.82 \pm 2.02$ Total score: 8
\begin{tabular}{|l|l|l|l|}
\hline S.N. & Preventive measures of teenage pregnancy & Frequency & Percentage \\
\hline 1. & Outreach in teen pregnancy prevention & 94 & 94 \\
\hline 2. & Youth development & 92 & 92 \\
\hline 3. & Involvement of family \& other caring adults & 90 & 90 \\
\hline 4. & Sexuality \& AIDS education & 86 & 86 \\
\hline 5. & Access to reproductive health & 86 & 86 \\
\hline 6. & Employment opportunities for adolescents & 84 & 84 \\
\hline 7. & Male involvement & 76 & 76 \\
\hline 8. & Community wide campaigns & 74 & 74 \\
\hline
\end{tabular}

Table 5 illustrates that majority (94\%) of respondents answered that outreach in teenage pregnancy prevention to reproductive health is necessary to prevent adolescent pregnancy. The majority $74 \%$ of respondent answered that community wide campaigns can prevent adolescent pregnancy. The total mean score regarding preventive measure of adolescent pregnancy was 6.82 with standard deviation of 2.02 out of total score 8 which indicates that the adolescents have adequate knowledge regarding preventive measure of adolescent pregnancy.

Table 6: Respondent's knowledge regarding consequences of teenage pregnancy to mother and baby $(n=100)$

\begin{tabular}{|l|l|l|l|}
\hline S.N. & $\begin{array}{l}\text { Knowledge regarding consequences of teenage pregnancy to } \\
\text { mother and baby }\end{array}$ & Frequency & Percentage \\
\hline 1. & Adequate & 74 & 74.0 \\
\hline 2. & Inadequate & 26 & 26.0 \\
\hline
\end{tabular}

Mean score \pm Standard deviation: 12.34 $\pm \mathbf{3 . 5 4} \quad$ Total score: $\mathbf{1 8} \quad$ Field Survey, 2013

Table 6 reveals that out of 100 respondents involved in the study, $74 \%$ had adequate knowledge regarding consequences of teenage pregnancy to mother and baby. The total mean score regarding consequences of teenage pregnancy to mother and baby as a whole was 12.34 with standard deviation of 3.54 out of total score 18 which indicates that the adolescents have adequate knowledge regarding consequences of teenage pregnancy to mother and baby.

Table 7. Respondent's knowledge on causes of teenage pregnancy $(n=100)$

\begin{tabular}{|l|l|l|l|}
\hline S.N. & Knowledge on causes of teenage pregnancy & Frequency & Percentage \\
\hline 1. & Adequate & 86 & 86.0 \\
\hline 2. & Inadequate & 14 & 14.0 \\
\hline
\end{tabular}

Mean score \pm Standard deviation: $\mathbf{6 . 3 8} \pm \mathbf{2 . 3 0}$ Total score: $9 \quad$ Field Survey, 2013

Table 7 shows that out of 100 respondents involved in the study 86 percent had the adequate knowledge regarding causes of teenage pregnancy. The total mean score was 6.38 with standard 
deviation of 2.30 out of total score of 9 which indicates that adolescent have adequate knowledge regarding causes of teenage pregnancy.

Table 8. Relation between knowledge regarding consequences of teenage pregnancy and type of family

\begin{tabular}{|c|c|c|c|c|c|c|c|}
\hline \multirow[t]{2}{*}{ S.N } & \multirow{2}{*}{$\begin{array}{ll}\text { Type } & \text { of } \\
\text { Family }\end{array}$} & \multicolumn{3}{|c|}{ Knowledge } & P value & $\overline{\text { Odds }}$ & CI at $95 \%$ \\
\hline & & Adequate & Inadequate & Total & 0.065 & 2.34 & 0.93 to 5.8 \\
\hline 1. & Joint & $44(82 \%)$ & $10(18 \%)$ & 54 & & & \\
\hline 2. & Single & $30(65 \%)$ & $16(35 \%)$ & 46 & & & \\
\hline 3. & Total & 74 & 26 & 100 & & & \\
\hline
\end{tabular}

Field Survey, 2013

Table 8 indicates that out of 54 respondents with joint family, $82 \%$ had adequate knowledge and out of 46 respondents with single family, only $65 \%$ had adequate knowledge. There is no relation between knowledge about the consequences of adolescent pregnancy and the type of family at $p$ value 0.05 level of confident as calculated $\mathrm{p}$ valve is 0.065 which is statistically insignificant. The calculated odds ratio is 2.34 .

Table 9: Relation between knowledge regarding consequences of teenage pregnancy and education level

\begin{tabular}{|c|c|c|c|c|c|c|c|}
\hline \multirow[t]{2}{*}{ S.N } & \multirow{2}{*}{$\begin{array}{l}\text { Educational } \\
\text { level }\end{array}$} & \multicolumn{2}{|c|}{ Knowledge } & \multirow[b]{2}{*}{ Total } & $P$ value & Odds ratio & CI at $95 \%$ \\
\hline & & Adequate & Inadequate & & \multirow{4}{*}{0.000} & \multirow[t]{4}{*}{0.18} & 0.071 to 0.49 \\
\hline 1. & Primary & $22(55 \%)$ & $18(45 \%)$ & 40 & & & \\
\hline 2. & Secondary & $52(87 \%)$ & $8(13 \%)$ & 60 & & & \\
\hline 3. & Total & 74 & 26 & 100 & & & \\
\hline
\end{tabular}

Field Survey, 2013

Table 9 indicates that out of 40 respondents with primary education, 55\% had adequate knowledge and out of 60 respondents with secondary education, $87 \%$ had adequate knowledge. There is relation between knowledge about the consequences of adolescent pregnancy and educational level at $\mathrm{p}$ value 0.05 level of confident as calculated $\mathrm{p}$ valve is 0.000 which is statistically significant. The calculated odds ratio is 0.18 .

\section{DISCUSSION}

The majority ( $84 \%$ of respondent) knew that maternal death could occur as consequences of teenage pregnancy whereas just $50 \%$ of respondents answered that eclampsia is also one of the consequences of teenage pregnancy to mother. Also the majority ( $86 \%$ ) of respondent knew that teenage pregnancy could lead to neonatal death. However, just (44\%) of respondents answered that cephalopelvic disproportion would occur as the consequences of teenage pregnancy to the baby. This study reveals that $74 \%$ had adequate knowledge on consequences of teenage pregnancy to mother and baby.

This study shows that majority ( $92 \%$ of the respondents) answered that illiteracy is a cause of teenage pregnancy. Minimum (34\%) of respondents responded that growing up in single parent also led to teenage pregnancy. This study reveals that $86 \%$ had adequate knowledge about the causes of teenage pregnancy. The results of this study are consistent with the study of Dangal (2005) that adolescent pregnancy is associated with poverty, growing up in single parent household, having a mother who have become mother at an adolescent age, early age at marriage, low level of education, and low level of contraceptive use. 
The study reveals that majority (91.8\% of the respondents) agreed that neonatal death was the consequences of teenage pregnancy. Other consequences reported by the respondents related to low birth weight $(89.8 \%)$, birth asphyxia $(79.6 \%)$, preterm labour $(73.5 \%)$, pregnancy induced hypertension $(53.1 \%)$. Minimum 51.0\% knew that eclampsia could occur as the consequences of teenage pregnancy. This finding of this study is supported in a study in India by Kumar et al (2007) wherein it is mentioned that complications in pregnancy induces hypertension (11.4\%), eclampsia $(4.9 \%)$ and premature onset of labour $(26.1 \%)$ in teenage. Teenage mothers also had increased incidence of low birth weight (50.4\%), premature deliver (51.8\%) and perinatal asphyxia $(11.7 \%)$, neonatal mortality $(3.85 \%)$.

This study shows that there is a relation between knowledge regarding the consequences of teenage pregnancy to mother and baby and education level. Adolescents of secondary level of education had adequate knowledge than those who have only primary education, which is similar with the study by Dangal (2005) that adolescent pregnancy is associated with low level of education. Similarly, the study supports the findings of Sharma AK, et. al., (2002), which asserts that teenage pregnant women are less educated.

In this study no significant association has been found between family structures with knowledge regarding the consequences of teenage pregnancy whereas in the study by Acharya, et al., (2008), a higher proportion of adolescent pregnant women (67\%) are found to be part of a joint family.

\section{CONCLUSION}

The study concludes that more than half of the respondents had adequate knowledge about consequences of teenage pregnancy to mother and baby and that there is a relation between knowledge regarding the consequences of teenage pregnancy and educational level. Education, advocacy and proper counselling can help reduce teenage pregnancy.

\section{ACKNOWLEDGEMENT}

I would like to extend my gratitude to my supervisor professor, Dr. Sarala Joshi for her continuous support and guidance. I would like to express my sincere thanks to $\mathrm{PhD}$ Centre for providing greater forum to publish the article. My special thanks go to staffs of $\mathrm{PhD}$ Centre for their support and guidance. I am also thankful to all the participants of my study.

\section{BIBLOGRAPHY:}

Acharya D.R., Bhattarai R., Amudha P., Van Teijilingen E. \& Chapman G. (2008), Factors associated with Teenage Pregnancy in South Asia: A Systematic Review, Health Science Journal, 4(1), 3-14

Central Bureau of Statistics. Population census 2001 national report. Kathmandu: National Planning Commission Secretariat and Central Bureau of Statistics-Government of Nepal in collabouration with UNFPA; 2002.

Choe,M.K., Thapa,S., Mishra,V. (2004). Early Marriage and early motherhood in Nepal. $J$. Biosoc. Sci, 1-20.

Dangal G. (2006), An Update on Teenage Pregnancy, Journal of Nepal Medical Association, 45(2), 262-272 
Department of Health Services. Annual report 2063/64 (2006/2007). Kathmandu: Department of Health Services, Government of Nepal; 2006.

Data from Population census of Nepal, 2001

Domenico DM, (2007), Adolescent Pregnancy in America: Causes and Responses, Journal for Vocational Special Needs Education, 30 (1).

Dr. Malla K.(2059), Thesis on Adolescent pregnancy: Associated risk factors with maternal $\&$ fetal outcome at maternity hospital, Institute of Medicine, Mahargunj Nursing Campus, Kathmandu

Garwick AW, Rhodes KL, Peterson-Hickey M \& Hellerstedt WL_ (2008), Native Teen Voices: adolescent pregnancy prevention recommendations, Journal Adolescent Health., 42(1), 81-88

Ghimire YC, (2004), Thesis on Youth pregnancy \& its outcome, NHRC Library, Book accession no.: $283,8-151$

Gokce B., Ozsahin A. \& Zencir M. (2006), Determinants of adolescent pregnancy in an urban area in Turkey: a population-based case-control study, Journal of biosocial science, 39(2), 301-311

Imamura M., Tucker J., Hannaford P., Astin M., Wyness L., Jahn A., Karro H, Olsen J. \& Temmerman M., (2007), Factors associated with teenage pregnancy in the European Union countries: a systematic review, European Journal of Public Health, 17(6), 630-636

Kumar A., Singh T., Basu S., Pandey S. \& Bhargava V., (2007), Outcome of teenage pregnancy, The Indian Journal of Paediatrics, 74(10), 927-939

Nepal Demographic health Survey. (2011).

UNFPA. (2007). A Child Marriage in Pakistan, A Taboo.

UNFPA. (2007). Giving Girls Today and tomorrow: Breaking the cycle of Adolescent Pregnancy. Retrieved June 4, 2013, fromhttp:/www.unfpa.org/webdav/site/global/shared/documents/publications.

UNFPA. (2007). Nepal Project Document: regional workshop on models for scaling up youth friendly services for SRH \& HIV prevention in South Asia. Kathmandu: UNFPA, CST for South and West Asia.

WHO. (Nov 2008). Age at First Marriage. 